\title{
O desenho universal para a aprendizagem na formação de professores: da investigação às práticas inclusivas
}

\author{
Ana Paula Zerbato ${ }^{1}$ \\ ORCID: 0000-0002-9624-2148 \\ Enicéia Gonçalves Mendes² \\ ORCID: 0000-0003-3673-0681
}

\section{Resumo}

As práticas pedagógicas realizadas na escolarização de estudantes público-alvo da Educação Especial em classes comuns são pensadas por meio de adaptações individualizadas do currículo e de flexibilizações. 0 Desenho Universal para a Aprendizagem (DUA), por outro lado, permite a criação de meios de acessibilidade ao ensino para um aprendizado sem barreiras. Assim, este estudo consistiu em investigar se um programa de formação de professores baseado nessa temática resultaria em práticas que alcançassem maior participação e aprendizagem do estudante público-alvo da Educação Especial na classe comum. Como metodologia, optou-se pela pesquisa colaborativa para produzir conhecimento e prover formação docente. Participaram do estudo dez professores da educação básica e sete estudantes de licenciaturas. 0 programa resultou em onze encontros, envolvendo várias ferramentas formativas, como casos de ensino fictícios e reais, roteiros de discussão dos casos e elaboração de planos de aula baseados no DUA. Os dados coletados foram organizados, sintetizados e apresentados de maneira a ilustrar os resultados do programa formativo, baseados em três casos, selecionados pelas professoras em exercício e em função da dificuldade que tinham de promover a participação e aprendizagem de determinado estudante. As aulas foram elaboradas coletivamente, implementadas pelas professoras e registradas em diário de campo. Os resultados apontaram elementos convergentes e divergentes entre os achados desta investigação e os estudos teóricos sobre a temática. Concluiu-se que as estratégias formativas pautadas nos pressupostos do DUA e da colaboração demonstraram-se como ferramentas potencializadoras no desenvolvimento de ações docentes condizentes com a diversidade, bem como na formação inicial e continuada dos participantes.

\section{Palavras-chaves}

Educação especial - Desenho universal para a aprendizagem - Inclusão escolar - Formação de professores - Pesquisa colaborativa.

\footnotetext{
1- Universidade de São Paulo, São Paulo, SP, Brasil. Contato: apzerbato@gmail.com

2- Universidade Federal de São Carlos, São Carlos, SP, Brasil. Contato: eniceia.mendes@gmail.com
} 


\section{The universal design for learning in teacher training: from investigation to inclusive practices}

\section{Abstract}

The pedagogical practices carried out in the schooling of students who are the target audience of Special Education in regular classes are designed through individualized adaptations of the curriculum and flexibility. The Universal Design for Learning (UDL), however, allows for the creation of accessible means of teaching for barrier-free learning. Thus, this study consisted of investigating whether a teacher training program based on this theme would result in practices that achieve greater participation and learning of the target public student of Special Education in the regular class. As a methodology, the collaborative research was chosen to produce knowledge and provide teacher training. Ten basic education teachers and seven teaching undergraduate students participated in the study. The program resulted in eleven meetings, involving various training tools, such as fictional and real teaching cases, case discussion scripts and preparation of lesson plans based on the UDL. The collected data were organized, synthesized and presented in order to illustrate the results of the training program, based on three cases, selected by the in-service teachers and due to the difficulty they had to promote the participation and learning of a particular student. The classes were collectively designed, implemented by the teachers and recorded in a field diary. The results pointed to convergent and divergent elements between the findings of this investigation and theoretical studies on the subject. It was concluded that the training strategies based on the assumptions of the UDL and collaboration proved to be potentiating tools in the development of teaching actions consistent with diversity, as well as in the initial and continuing education of the participants.

\section{Keywords}

Special education - Universal design for learning - School inclusion - Teacher training - Collaborative research.

\section{Introdução}

Em decorrência de uma política de inclusão escolar ${ }^{3}$ adotada a partir de 2003, observou-se o aumento crescente da escolarização de estudantes público-alvo da Educação Especial ${ }^{4}$ em escolas regulares. 0 número de matrícula desses estudantes em

3- Neste trabalho será utilizado o conceito de inclusão escolar, compreendido em vários níveis (filosófico, político e prático, normativo, investigativo etc.), mas com um único foco: o processo de escolarização de estudantes do público-alvo da Educação Especial no contexto da classe comum de escolas regulares. 0 termo educação inclusiva, por outro lado, se refere à população de estudantes historicamente excluídos da escola e embora envolva alunos PAEE, não se reduz a eles.

4- A Política de Educação Especial na Perspectiva da Educação Inclusiva de 2008 (BRASIL, 2008) define como público-alvo da Educação Especial os alunos com deficiência (intelectuais, sensoriais e motoras), transtornos globais de desenvolvimento e altas habilidades/superdotação. 
classes comuns decuplicou nos últimos dezessete anos, passando de 110.536 em 2002, para 1.090.805 em 2019 (INEP, 2002, 2019). À medida que esses estudantes ingressaram nas classes comuns, novos desafios surgiram para os professores, no sentido de assegurar o ensino para todos em turmas cada vez mais heterogêneas.

A princípio, a educação dos alunos público-alvo da Educação Especial era realizada de maneira distinta do ensino planejado aos demais. A estratégia adotada foi tentar, via adaptações, acomodações ou flexibilizações, conciliar, na medida do possível, suas necessidades educacionais específicas com as demandas do currículo de base comum. Entretanto, essas tentativas foram praticamente ineficazes porque a ênfase ainda recaía num currículo baseado no déficit e na sua compensação. Enquanto isso, o currículo comum ainda parecia inacessivel para muitos, desafiando os benefícios da escolarização em classe comum de escolas regulares.

Com o tempo, mais do que agir sobre o estudante diferente, as pesquisas em Educação Especial começaram a mostrar que as políticas inclusivas deveriam visar à reestruturação dos sistemas de ensino e das escolas, contemplando a diversidade dos alunos. Mais do que garantir o ingresso, seria necessário investir na formação dos educadores, em recursos materiais, humanos e tecnológicos, em mudanças nas práticas pedagógicas e na organização de serviços de apoio, de modo a assegurar o ingresso e a permanência de todas as crianças e jovens na escola (STAINBACK; STAINBACK, 1999; AINSCOW; BOOTH; DYSON, 2006).

Cabe destacar ainda que, em países com indicadores de baixa qualidade de ensino básico, como é o caso do Brasil, seria utópico considerar que o sucesso de políticas inclusivas se resumiria à garantia do ingresso de crianças numa escola que tem um dos piores desempenhos. Portanto, são necessárias políticas que melhorem o ensino para todos, indistintamente, e não apenas para aqueles que apresentam alguma necessidade educacional especial.

No caso dos estudantes público-alvo da Educação Especial, a política de escolarização em classes comuns de escolas regulares mostrou ainda que grande parte desses estudantes - uma estimativa de 80 por cento desse alunado - requer apenas um modelo de uma boa escola, ao passo que apenas uma minoria precisaria de metodologias diferenciadas ou especializadas, não contempladas no ensino comum (WANG; REYNOLDS; WALBERG, 1995). Assim, o direcionamento da pesquisa sobre inclusão escolar passou a ser mais voltado para o desenvolvimento das chamadas práticas pedagógicas universais, ou que se mostram efetivas para todos, do que para as estratégias especializadas. Assim que o ensino na classe comum melhora para todos, é possivel ter a dimensão exata de quais estudantes precisariam de apoios adicionais, para os quais o currículo da classe não é suficiente.

A partir desse momento, a lógica na organização da sistemática de apoios para ambientes educacionais inclusivos deixou de ser baseada em propostas remediativas, centradas no estudante com deficiência, como infelizmente é o caso do atendimento educacional especializado extraclasse proposto na política de Educação Especial no Brasil (BRASIL, 2008). 0 que a literatura científica tem apontado é a necessidade de se investir num Sistema de Suporte Multicamada (SSM), em que o ensino e as intervenções são fornecidas aos estudantes em níveis variados de intensidade (camadas), com base em suas necessidades. 0 primeiro nível seria o das intervenções universais, que pretendem melhorar 
o ensino para todos no contexto da classe comum. Quando esse ensino melhorado na classe comum não for satisfatório, são acrescentadas intervenções suplementares direcionadas. Se, por sua vez, esse nível de suporte não for suficiente, lança-se mão do terceiro nível: as intervenções intensivas (tempo aumentado e foco reduzido) para indivíduos ou pequenos grupos (KOVALESKI; BLACK, 2010).

$\mathrm{Na}$ perspectiva da Educação Especial, que historicamente buscou responder ao processo de ensino para pequenos grupos e focado nas necessidades diferenciadas baseadas no déficit, o desafio tem sido desenvolver abordagens pedagógicas mais universais, que melhorem o ensino na classe comum para todos. Considerando-se que, ao final, se o professor não conseguir lidar com a variedade de estudantes em sala de aula, todas as boas intenções que encerram as políticas e práticas inclusivas serão inúteis. Isso posto, cabe investigar como preparar professores para lidar com a diversidade nas escolas (WANG; FITCH, 2010).

Nesse sentido, o Desenho Universal para Aprendizagem (DUA) tem sido apontado como abordagem promissora pela literatura sobre inclusão escolar, mas pouco explorada no contexto nacional. Dessa forma, o objetivo deste estudo consistiu em investigar se um programa de formação de professores baseado nessa temática poderia resultar em práticas que alcançassem maior participação e aprendizagem do estudante público-alvo da Educação Especial no contexto da classe comum.

\section{Desenho Universal para a Aprendizagem (DUA)}

A proposta de ensino baseada no DUA visa ao planejamento do ensino e acesso ao conhecimento para todos os estudantes. Ela considera as especificidades individuais do aprendizado, pressupõe que todos os indivíduos são diferentes e possuem ritmos e estilos variados para aprender. A abordagem fornece um referencial para professores e outros profissionais especializados na elaboração de práticas e estratégias que foquem na acessibilidade, tanto em termos físicos quanto em termos de serviços, na busca de caminhos educacionais para o aprendizado sem barreiras (CAST UDL BOOK BUILDER, 2013).

Assim, ao contrário de se pensar nas práticas usuais de adaptação curricular, ou em alguma atividade específica para determinados estudantes público-alvo da Educação Especial, planejam-se formas diferenciadas e variadas de se ensinar o currículo para todos os estudantes (ALVES; RIBEIRO; SIMÕES, 2013). Ao elaborar materiais para o aprendizado de conteúdos curriculares tendo em vista os estudantes público-alvo da Educação Especial, por exemplo, tal recurso normalmente é pensado como de uso exclusivo de um estudante específico. Na perspectiva do DUA, a proposta é a construção de práticas universais, disponibilizando o mesmo material para todos os alunos, como forma de contribuir para o aprendizado de outros estudantes.

De acordo com Alves, Ribeiro e Simões (2013), essa perspectiva de ensino é embasada em três princípios: i) o reconhecimento de informações a serem apreendidas (princípio da representação); ii) as estratégias para operar no processamento da informação (princípio da ação e expressão); e iii) a motivação do aluno (princípio do engajamento). Dessa forma, sua estrutura pretende embasar o planejamento do ensino para a oferta de oportunidades de aprendizagem para todos, por meio do uso de estratégias e materiais diversificados, 
que deem suporte para estilos e ritmos de aprendizado variados. 0 desafio para a pesquisa consistiu em investigar como proporcionar formação aos professores para planejarem o ensino fundamentando-se na estrutura do DUA.

\section{Formação de professores sobre DUA}

A inclusão escolar exige cada vez mais que os professores do ensino comum e os professores especialistas sejam preparados em seu processo de formação para o atendimento de estudantes do público-alvo da Educação Especial (BUENO, 2008). Ressalta-se, portanto, a necessidade de investimentos em programas de formação inicial e continuada, que se voltem para a reflexão do cotidiano escolar, possibilidade de troca de experiências e construção coletiva de novos saberes pedagógicos (BEAUCHAMP, 2002).

Além disso, é fundamental valorizar e implementar uma cultura de trabalho colaborativa, pois ainda que os professores do ensino comum tenham uma formação inicial de boa qualidade para responder às demandas do processo de inclusão escolar dos estudantes PAEE (Público-Alvo da Educação Especial), eles necessitarão do apoio especializado de professores da Educação Especial ou de outros profissionais para o desenvolvimento de estratégias e de materiais, utilização de recursos de baixa e alta tecnologia, entre outros (VITALIANO; MANZINI, 2010). De acordo com Lopes (1997, p. 574), é indispensável uma "formação de professores que reflita sobre sua própria prática, bem como para a utilização da reflexão como instrumento de desenvolvimento do pensamento e da ação" (p. 574). Diante desse contexto, neste estudo optou-se por elaborar um programa de formação docente na perspectiva colaborativa, visto que:

Em grupos de colaboração, os professores debatem sobre o progresso do processo, refletem criticamente o ensino, partilham de uma linguagem para se referirem a conceitos, constroem e reconstroem juntos conhecimentos acerca do ensino, procedendo desta forma, à autorregulação da sua aprendizagem e das suas práticas. A formação em contexto colaborativo necessita do compartilhamento das decisões por todos os envolvidos, que acabam por responsabilizarem-se pela produção conjunta, segundo suas necessidades, possibilidades e interesses [...]. (BASTOS; HENRIQUE, 2016, p. 305).

Nesse sentido, torna-se promissor o desenvolvimento de pesquisas com foco, concomitantemente, na produção de conhecimento e na formação de professores e de profissionais na perspectiva da colaboração, no intuito de contribuir para o processo de universalização do acesso e da melhoria do ensino ofertado a todos os estudantes do públicoalvo da Educação Especial (CAPELLINI, 2004; RABELO, 2012; VILARONGA, 2014).

Ao se pensar num modelo de formação que tratasse das práticas pedagógicas inclusivas realizadas na escola, da reflexão sobre elas e da construção de novos saberes, a perspectiva da pesquisa e da formação colaborativa, fundamentada no conceito e princípios do DUA, foi escolhida, pois considera-se que, se o professor, em parceria com profissionais especializados, planejar, implementar e avaliar suas práticas pedagógicas pautadas nos princípios do DUA, ele conseguirá promover a participação e aprendizado de todos em sua sala de aula, inclusive do estudante público-alvo da Educação Especial: 


\begin{abstract}
Garantir o acesso à escola regular constitui a dimensão mais fácil de alcançar no processo de inclusão, pois depende sobretudo de decisões de natureza política. Já assegurar a aprendizagem e o sucesso na aprendizagem envolve mudanças significativas nas formas de conceber a função da escola e o papel do professor no processo de ensino e aprendizagem. Trata-se, portanto, de equacionar processos pedagógicos inclusivos que permitam o envolvimento efetivo de crianças e jovens com necessidades educacionais especiais na aprendizagem [...]. Tal necessidade está associada ao aparecimento do conceito Universal Design for Learning (UDL) nos anos 90 [...]. (NUNES; MADUREIRA, 2015, p. 7).
\end{abstract}

De acordo com Toledo e Vitaliano (2012), observa-se, nos últimos anos, a produção de muitos estudos que contemplam as características exigidas para a realização de uma pesquisa científica e, ao mesmo tempo, provê a formação de professores. Para os autores, a pesquisa colaborativa se refere a "[...] uma proposta de investigação educacional, capaz de articular pesquisa e o desenvolvimento profissional por intermédio de aproximações entre universidades e escolas" (p. 323). Mizukami et al. (2003) apontam que a pesquisa colaborativa pode potencializar a melhora do desenvolvimento profissional por meio de oportunidades de reflexão sobre práticas, críticas partilhadas e mudanças apoiadas. Na investigação colaborativa, procura-se progredir por meio da reflexão e prática conjunta entre pesquisados e pesquisador para produção de novos conhecimentos.

Assim, tendo em vista as vantagens da pesquisa colaborativa para produzir conhecimento e prover formação, foi realizada uma investigação ${ }^{5}$ com o objetivo de desenvolver, implementar e avaliar um programa de formação, tendo em vista os desafios da inclusão escolar e o referencial do DUA (ZERBATO, 2018). A meta do programa era de, gradualmente, levar os participantes a aplicarem esse conhecimento no planejamento de uma aula real.

\title{
Inclusão escolar e desenho universal para a aprendizagem: conhecer para implementar
}

Tendo em vista a necessidade de manter a coerência entre teoria e prática, o programa de formação foi organizado e implementado tomando-se como base os três princípios do DUA, ou seja, instrumentos e estratégias fundamentados nos princípios do Engajamento, da Representação e da Ação e Expressão foram adotados e estão sintetizados a seguir:

A) Estratégias de engajamento: realização de atividades para identificação dos conhecimentos preexistentes dos participantes, reflexão sobre assuntos relacionados à inclusão escolar e ao contexto em que atuavam, levantamento de demandas e dúvidas, atividades em pequenos grupos e individuais sobre práticas pedagógicas já utilizadas, levantamento de conhecimentos sobre DUA e compartilhamento dos desafios educacionais vivenciados por eles. Estratégias utilizadas: diálogo entre o grupo, dinâmicas, escrita e relatos orais sobre o caso de ensino vivenciado pelos participantes no momento da formação.

5- Pesquisa submetida e aprovada pela Plataforma Brasil (parecer n. 1.041.571). 
B) Estratégias de representação: (apresentação do conteúdo programático da formação): deu-se por meio de debates durante as reuniões, leitura do texto escrito, apresentação de síntese dos assuntos abordados, exemplos de estratégias embasadas no DUA e análise de casos de ensino fictícios e reais. Os recursos utilizados foram apresentações em slides, vídeos, imagens, textos, materiais concretos para elaboração de materiais didáticos propostos no planejamento das aulas baseadas no DUA, palestras de especialistas, diálogo e trocas.

C) Estratégias de ação e expressão: (estratégias para coleta de dados sobre os aprendizados dos participantes durante a formação): foram realizadas leituras e discussões coletivas dos textos didático-formativos organizados pelo pesquisador e apresentados pelos participantes, em duplas, por meio da utilização de apresentações em slides, vídeo, imagens, dinâmicas. Também foram utilizadas atividades escritas de reflexão sobre os textos, debates sobre os assuntos abordados, além da atividade prática de elaboração colaborativa de um plano de aula pautado no DUA, aplicação da atividade elaborada, apresentação da atividade por meio de imagens, fotos, registros escritos no diário de campo e relatos orais.

Cada encontro do programa de formação foi elaborado e reelaborado com os participantes de acordo com as demandas e o andamento de onze encontros formativos. Conforme a realização dos encontros, uma avaliação das atividades formativas e o replanejamento para a próxima reunião eram feitos, a fim de atender às demandas do grupo, mas sem perder de vista os objetivos da formação. Todos os materiais teóricodidáticos elaborados estavam fundamentados em estudos internacionais sobre o DUA (NELSON, 2014; ALVES; RIBEIRO; SIMÕES, 2013; NUNES; MADUREIRA, 2015).

Tendo em vista a meta de proporcionar um ambiente de formação colaborativo, adotou-se uma amostragem mista de participantes, que contemplou professores em exercício e estudantes de licenciaturas (futuros professores), objetivando a troca de experiência teórica e prática entre os participantes que buscaram o programa enquanto formação continuada e os que estavam em formação inicial.

Ao todo, participaram do programa dez professores do ensino comum, que atuavam na rede de Educação Básica nos diferentes níveis de ensino: cinco na Educação Infantil, três nos anos iniciais do Ensino Fundamental e dois nos anos finais do Ensino Fundamental (professores de Língua Portuguesa). Todos já haviam trabalhado em turmas com estudantes do público-alvo da Educação Especial. Participaram também sete estudantes de cursos de licenciatura, sendo: quatro da licenciatura em Educação Especial, um estudante de Pedagogia, um aluno de Ciências Biológicas e um estudante de Física. Grande parte já havia realizado o estágio supervisionado em turmas contendo o público-alvo da Educação Especial.

Ao longo do programa, os participantes deveriam planejar coletivamente uma aula baseada nos princípios do DUA. A atividade se desenvolveu por meio da troca de informações entre o grupo durante as reuniões precedentes à elaboração do plano de aula. Os estudantes participantes traziam contribuições relacionadas aos conhecimentos adquiridos nos cursos de licenciatura e aos conhecimentos aprendidos com a literatura sobre DUA disponibilizada. Também se contou com a colaboração de especialistas da universidade, que ministraram 
algumas palestras aos participantes sobre estratégias e materiais que poderiam ser usados para o ensino em turmas com e sem alunos público-alvo da Educação Especial.

A construção desses planos foi pautada em pesquisas internacionais sobre DUA, como a de Nunes e Madureira (2015), que apresentaram em seu estudo um modelo de planejamento fundamentado nos princípios do DUA e contemplava como componentes essenciais do currículo: "i) objetivos, ii) estratégias de ensino, iii) materiais e recursos e iv) avaliação" (p. 37).

0 protocolo para elaboração do plano de aula foi organizado em duas partes. A primeira parte continha a identificação do professor, turma, informações sobre o estudante PAEE e o contexto da sala comum/escola. As professoras deveriam colocar o maior número de informações que tivessem sobre o estudante, sua família, a relação com a escola, os atendimentos ofertados, suas potencialidades e dificuldades, estilos de aprendizagem e características relevantes do contexto em que acontecia o ensino. A segunda parte tratava especificamente do próprio ato de ensinar, por isso deveriam registrar a área trabalhada no plano de aula, os objetivos, a metodologia, os recursos necessários e a avaliação. Também precisariam contemplar os três princípios do DUA: estratégias de engajamento, de apresentação do conteúdo e, por último, estratégias de ação e expressão dos conteúdos aprendidos pelos estudantes.

Ao final, foram produzidos dez planos de aula, construídos em colaboração entre as professoras do ensino comum, pesquisadoras e estudantes da graduação. Do total de planos de aula elaborados, nove foram efetivamente colocados em prática e apenas uma professora não conseguiu realizar a atividade, pois estava na função de coordenadora pedagógica da escola em que atuava.

Os dados analisados procederam da coleta realizada por diferentes fontes, tais como as filmagens registradas dos encontros, as produções de tarefas, os registros e os relatos dos participantes. Entretanto, o particular interesse de análise focalizado nesse estudo foram os planos de aula elaborados coletivamente e aplicados pelas professoras em exercício, bem como os seus diários de campo em que registraram a implementação da atividade planejada.

Devido à necessidade de delimitação e à impossibilidade de descrever e analisar todos os nove planos e os resultados dessas implementações, foram selecionados três casos para ilustrar como os participantes, em colaboração, planejaram e implementaram seus planos de ensino baseados no DUA. 0 critério de seleção foi intencional para exemplificar as possibilidades do ensino baseado no DUA em turmas de níveis de ensino variados, sendo um caso da Educação Infantil, o segundo dos Anos Iniciais ( $4^{\circ}$ ano) e o terceiro dos Anos Finais ( $6^{\circ}$ ano) do Ensino Fundamental.

Resultados e discussões: da zona de conforto à potencialização das práticas

Os resultados foram organizados na forma de relatos de casos, de modo a sintetizar as informações coletadas do plano de aula e do diário de campo. Cada caso relatado contém uma breve descrição do desafio da professora na classe comum com o ensino para um aluno público-alvo da Educação Especial, uma explicação de como ocorria o ensino 
para toda a turma, o que mudou no planejamento e as repercussões da aula baseada no DUA. Os resultados representam, portanto, uma descrição sintetizada, ilustrada com relatos verbais ou contidos em diários de campo das professoras participantes.

\section{Caso 1: engajamento e participação em atividades da Educação Infantil da professora Fátima}

Uma das preocupações da professora Fátima, em relação ao seu aluno-alvo, era a pouca ou nenhuma interação com as demais crianças, sua falta de atenção, a dificuldade na comunicação e a agressividade em determinados momentos. A professora já havia encaminhado a criança para avaliação psicológica, mas ainda não havia um diagnóstico conclusivo. Como uma das suas tarefas de rotina era a narração de histórias, ela tinha como objetivo promover a participação do estudante nessa atividade. Ela relatou que, normalmente, após a narração, chamava o aluno em sua mesa para lhe contar a história ouvida, entretanto, os demais alunos queriam contar a história à professora, fazendo da atividade uma tarefa longa e dispersiva. Diante desse contexto, a professora Fátima decidiu elaborar seu plano de aula baseado no DUA, com o objetivo de promover a socialização e a comunicação do aluno-alvo, assim como a organização da sequência de uma história já conhecida por ele e pelos demais colegas: "Os três porquinhos".

0 plano de aula contemplou três etapas fundamentadas nos princípios do DUA: i) estratégias de engajamento e motivação: manuseio do livro, dos personagens e do cenário que a professora construiu durante o programa de formação; ii) estratégias de representação: narração da história pela professora primeiramente, utilizando o livro e o material produzido, e depois a narração com o auxílio da turma; e iii) estratégias de ação e expressão: apresentação de um vídeo sobre a mesma história e roda de conversa. Em seu diário de campo e nos relatos filmados da apresentação da atividade, Fátima narrou que a atividade não ocorreu totalmente como foi planejada e que se surpreendeu com seus alunos:

No segundo dia, nada saiu como eu havia planejado. Foi melhor e mais espontâneo, porque eles tomaram a frente em quase todos os momentos! Quando comecei a contar a história, pedi a ajuda dos alunos. D. (o aluno-alvo) se levantou e também quis contar a história utilizando o livro. Fiquei muito surpresa com a reação dele. (Professora Fátima - Educação Infantil - Diário de Campo - 10/11/2015).

A estratégia utilizada pela professora foi a divisão da turma em dois grupos para o reconto da história. Cada aluno escolheu um personagem ou um cenário. A professora tomou o papel de narradora e um integrante do grupo ficou responsável por mostrar o livro para os demais apoiarem a dramatização. Entretanto, no transcorrer da tarefa, os alunos se sentiram tão à vontade na realização da atividade que eles próprios narraram e dramatizaram a história sem necessitar mais do seu apoio. 0 aluno-alvo participou ativamente da atividade sem a necessidade do apoio individualizado, algo que a professora normalmente lhe dava durante a realização das tarefas.

Retomando o seu planejamento, na terceira etapa da atividade, a turma assistiu a um vídeo sobre a história e foi realizada uma roda de conversa. De acordo com o seu 
diário de campo, enquanto conversavam sobre a história e como tinha sido a atividade da dramatização, um dos alunos que havia faltado no dia anterior começou a chorar por não ter participado da atividade. Nesse momento:

[...] os alunos pediram para fazermos de novo para o amigo participar. Então entreguei o material a eles e deixei que fizessem a encenação, um foi orientando o outro e todos participaram. Acho que esse foi o melhor feedback que eu poderia ter! (Professora Fátima - Educação Infantil Diário de Campo - 10/11/2015).

Os primeiros relatos da professora revelavam uma compreensão de que o seu estudante-alvo continuamente necessitaria de um atendimento individualizado ou de uma estratégia diferente dos demais. Num primeiro momento, supunha que ele não era capaz de participar da mesma atividade e que, dessa forma, ela deveria sempre pensar numa atividade específica ou diferenciada. Ao realizar estratégias com todos os alunos, a professora se surpreendeu com os resultados e, no momento da apresentação da atividade na reunião do programa de formação, um dos estudantes a questionou:

Estudante Aline: Mesmo dando todo esse trabalho, você faria esse tipo de atividade novamente? Professora Fátima: Ah, com certeza! [...] As atividades por meio de histórias foram por causa dele mesmo (aluno-alvo). Eu até coloquei mais vezes na semana. (Trecho transcrito da Reunião n. 9 - 11/11/2015).

\section{Caso 2: engajamento e participação da turma do $4^{\circ}$ ano do Ensino Fundamental da professora Alda}

No momento da formação, a professora Alda atuava como professora eventual de uma escola estadual, assim, não possuía uma turma fixa e substituía os professores regentes quando eles faltavam. A atividade pautada no DUA foi pensada para uma turma de $4^{\circ}$ ano do Ensino Fundamental, na qual a professora identificou um estudante com dificuldades de aprendizagem, bastante tímido e de pouca interação com os colegas. Por isso, seu objetivo, além do reconto da fábula pela turma, era estimular a socialização e a expressão oral dos estudantes.

Para engajamento dos estudantes, a professora possibilitou o livre manuseio dos personagens e cenários que havia construído em colaboração com o grupo de participantes durante o programa de formação. Além disso, introduziu a proposta de apresentação da fábula pelos alunos para uma outra turma da escola. Os estudantes se empolgaram e aceitaram realizar a atividade. Como estratégia de apresentação do conteúdo, a professora narrou a fábula "O Rato do campo e da cidade", com apoio do livro da história. Como estratégia de ação, expressão e avaliação dos conhecimentos aprendidos pela turma, realizou o reconto da fábula com apoio dos personagens para uma outra classe da escola.

De acordo com os relatos da professora e dos registros apresentados, pode-se induzir que a atividade foi desenvolvida com envolvimento e empolgação por todos os estudantes. Uma atividade que comumente seria realizada de maneira expositiva e com apenas o apoio do livro, foi realizada de uma maneira mais lúdica, com a utilização de materiais de baixo 
custo e por meio de diferentes estratégias que possibilitaram a participação da turma em geral por meio da encenação. Durante a apresentação da atividade na reunião de formação, a professora relatou que muitos estudantes, que normalmente não se interessavam pelas atividades propostas, se comprometeram com a tarefa nesse dia. Os dados indicaram que a realização da atividade de maneira diferenciada estimulou o maior envolvimento de todos e abriu possibilidades para esses estudantes, que pouco se envolviam, aprenderem.

\section{Caso 3: mudanças nas formas de representação e expressão na atividade da professora Marília ( $6^{\circ}$ ano do Ensino Fundamental)}

A atividade executada pela professora Marília envolveu a disciplina de Língua Portuguesa e o conteúdo Elementos da Narrativa. Depois de uma aula expositiva para apresentação da temática, cada grupo de estudantes deveria escrever um texto envolvendo os elementos tempo, espaço, personagens e conflitos. De acordo com as especificidades do estudante público-alvo da Educação Especial, a professora avaliou e planejou uma atividade em grupo que envolveu o engajamento dos estudantes na produção de um texto escrito coletivamente para expressarem seus aprendizados. Posteriormente, os grupos apresentaram seus textos oralmente. Não houve necessidade de adaptações específicas, apenas o material de registro do estudante público-alvo da Educação Especial era diferente dos demais, ou seja, em vez da utilização de caderno e caneta, ele utilizava um computador para escrever.

Com relação ao desenvolvimento das práticas pedagógicas da professora, destaca-se o seu relato inicial durante as primeiras reuniões: "Terminarei o ano com a certeza que não contribui em nada no processo de ensino e aprendizagem desse aluno". (Trecho do caso de ensino da professora Marília - 23/09/2015). Na décima reunião de formação, ao apresentar a atividade baseada no DUA, a professora narrou:

J. tem um notebook que é adaptado para ele. Ele tem uma mesa, também adaptada, que encaixa nele. Então o mouse é trazido a uma distância que ele consiga manuseá-lo e o teclado é maior para que ele vá selecionando as letras sozinho. Como ele sabe ler, eu chamo a cuidadora, ela senta com ele e dou o texto para ela. Algumas vezes ela vai mostrando, outras vezes ela lê para o aluno e ele realiza a atividade no computador. Então eu tenho um pen drive que eu já combinei com ele: J. esse pen drive é seu e meu. Aí vou lá entrego o pen drive para ele com a atividade, ele faz a atividade dele e me traz o pen drive. (Trecho do relato da professora Marília - $6^{\circ}$ ano - em sua apresentação da atividade baseada no DUA - 25/11/2015).

0 detalhe da descrição dos recursos utilizados pelo aluno, o estabelecimento de parcerias e o arriscar-se no desenvolvimento de estratégias de acesso ao currículo demonstraram a potencialização do seu ato de ensinar e os progressos no aprendizado do estudante-alvo, sem que a professora demandasse o planejamento de atividades curriculares individualizadas. A diferenciação no ensino foi apenas no meio pelo qual o aluno recebia a atividade, ou seja, o computador. A contribuição do estudante-alvo para seu grupo de trabalho foi a participação na construção coletiva do texto, na qual todos discutiriam primeiro a produção textual e, ao final, um aluno registraria de forma escrita. 
A apresentação oral do produto final elaborado pelos grupos de trabalho aconteceu na aula seguinte, entretanto, o aluno-alvo não estava presente.

\section{Da idealização às possibilidades}

De acordo com Nunes e Madureira (2015), a perspectiva do DUA remete à necessidade e à relevância dos profissionais desenvolverem planejamentos de intervenção pedagógica que "disponibilizem formas diversificadas de motivação e envolvimento dos alunos, que equacionem múltiplos processos de apresentação de conteúdos a aprender e, por último, que possibilitem a utilização de diversas formas de ação e expressão" (p. 40), conforme as habilidades e potencialidades de cada sujeito aprendiz. 0 instrumento elaborado durante a pesquisa para o planejamento de uma aula pautada nos princípios do DUA buscou atender a esses requisitos, constituindo uma proposta de planejamento em conjunto, integrando os elementos do DUA nas práticas já desenvolvidas pelas professoras para potencializar o seu ensino e possibilitar o acesso e a participação de todos.

A apresentação de cada caso de ensino, o contexto educacional e as características dos estudantes público-alvo da Educação Especial que as professoras participantes atendiam e que seriam alvo no plano de aula estruturado pelo DUA fomentaram elementos relevantes para o desenvolvimento da atividade de planejamento coletivo e colaborativo. Propiciou-se também um ambiente com potencial de troca de informações e experiência entre os participantes que pensaram juntos em atividades e estratégias, baseados em conhecimentos teóricos e práticos, para acessibilidade e aprendizado de toda a turma. Assim, os pressupostos da colaboração, em união com os princípios do DUA, se mostraram ferramentas potentes para o planejamento de atividades mais inclusivas.

Nesse sentido, a colaboração precisa ser encarada pelos profissionais como uma "filosofia de trabalho entre profissionais da educação com conhecimentos e experiências diferenciadas" (RABEL0, 2012, p. 53). Isso significa ter uma atitude "filosófica e crítica de olhar para um colega de trabalho como parceiro e construir uma experiência conjunta de trabalho pedagógico no contexto escolar e da sala de aula" (RABELO, 2012, p. 53).

Observou-se, durante as reuniões formativas, que o diálogo e a troca de conhecimentos ocorreram, as professoras acataram sugestões do grupo e se motivaram a incrementar inovações nas práticas já desenvolvidas por elas, produzindo material de baixo custo, mudando estratégias de representação e expressão, estimulando o engajamento, visando à potencialização das atividades para participação e aprendizado de todos. 0 fato de 0 grupo se assumir como protagonista da ação durante o programa de formação sobre DUA tornou as atividades estimulantes, na medida em que compartilharam as suas experiências, concepções e tomada de decisão sobre suas ações.

Notou-se o envolvimento do grupo com os desafios suscitados, coletiva ou individualmente, sobre o que era desconhecido por eles e que se apresentava por meio de uma temática que não era de domínio da maioria dos participantes, nesse caso, o conceito de DUA. Entretanto, todos se mostraram empenhados em tentar experimentar de forma compartilhada os aprendizados adquiridos por meio das práticas elaboradas de acordo com a proposta do programa de formação. 
Para King-Sears (2014), os princípios e estratégias do DUA possibilitam aos profissionais delimitar seus objetivos, as atividades e práticas de ensino que serão utilizadas e os meios de avaliação apropriados a cada aluno, de modo a permitir o acesso ao currículo e a aprendizagem de todos. Ao reconhecer que seus alunos têm estilos e ritmos de aprendizado diferentes, a professora Fátima, por exemplo, compreendeu a necessidade de desenvolver múltiplos meios para o envolvimento e aprendizado de todos.

De acordo com Johnson-Harris e Mundschenk (2014), essa professora aproveitou seu tempo e energia, ampliando a dinâmica da sala de aula. Além de fazer a atividade ocorrer mais naturalmente, o benefício adicional do planejamento do ensino pautado nos princípios do DUA foi que os estudantes público-alvo da Educação Especial foram capazes de se envolver com o material de forma mais motivada, permitindo, assim, o seu desenvolvimento a partir de suas habilidades, ao mesmo tempo que o apoio pode ser oferecido. A análise dos resultados da atividade da professora da Educação Infantil mostrou que o conhecimento teórico sobre DUA, apresentado no programa de formação, possibilitou a inovação de sua prática, de modo a engajar todos os estudantes para aprender.

Gostei muito da atividade e principalmente da forma como foi conduzida pelos alunos. E o melhor foi ver como o aluno-alvo ficou à vontade com a atividade, pois em nenhum momento ele mostrou timidez, frustração ou agressividade com os colegas que estavam ao lado dele. (Professora Fátima - Educação Infantil - Diário de Campo).

A atividade elaborada e realizada pela professora Fátima (Educação Infantil) pareceu ter superado suas expectativas quanto ao envolvimento e ao aprendizado dos alunos. Nesse sentido, pode-se avaliar que o objetivo da atividade foi alcançado, pois houve o engajamento de todos, a interação do aluno-alvo com os demais, promoveu-se a oralidade e os alunos demonstraram conhecimentos em relação à história e à sequência dos fatos no momento da recontagem. De acordo com Nunes e Madureira (2015), o DUA consiste em uma abordagem curricular que auxilia os docentes a identificarem e removerem as barreiras de aprendizagem, permitindo aos estudantes formas diferentes de se envolver e aprender e, principalmente, reduz a necessidade de adaptações curriculares individuais, favorecendo o desenvolvimento de práticas pedagógicas mais inclusivas. Assim, ao invés de planejar duas aulas diferentes, uma para o aluno público-alvo e outra para a turma, o DUA propõe que um único plano de aula que seja acessivel a todos.

Os participantes do estudo também refletiram sobre a importância de a escola criar um ambiente de compartilhamento de materiais e atividades, de um espaço construído com esse objetivo, um ambiente de colaboração e de troca de práticas vivenciadas que poderia diminuir a necessidade de cada professor construir novos materiais para cada turma e para cada situação de ensino, estimulando um trabalho de colaboração, de troca de informações e ideias entre eles. Um material construído por um professor poderia ser utilizado por outro com objetivos diferenciados, desde que acervos virtuais ou reais fossem desenvolvidos.

Apesar de o ambiente escolar ser um espaço coletivo, observa-se que ainda é forte a cultura do trabalho solitário entre os professores, bem como hábitos de armazenamento 
de recursos e materiais em armários trancados para não estragar, por exemplo, ou ainda, a disposição de livros nas bibliotecas ou outros materiais escolares em locais que impossibilitam o seu manuseio por estudantes, com a justificativa de evitar danificálos. Esses hábitos, muitas vezes, dificultam o encontro de respostas para a maior parte das dificuldades apresentadas pelos professores no ato de ensinar e impossibilitam a concretização de processos reais de aprendizagem para os alunos com dificuldades.

Considerando o desafio dessa mudança na cultura escolar, a formação continuada foi verificada, neste estudo, como estratégia em potencial para o convite à experimentação de novas práticas em ambiente escolar. É o que se pode observar em relação à professora Marília ( $6^{\circ}$ ano), que apresentava resistência e sentimento de despreparo para ensinar o estudante-alvo, apontando, inclusive, que em nada contribuiria para o aprendizado dele. Ao longo do programa de formação, ela arriscou-se em algumas estratégias e estabeleceu uma parceria com a cuidadora que o acompanhava. Seu estudante-alvo não tinha movimentos que possibilitassem a realização das atividades sozinho, por isso, muitas vezes ela contou com o apoio de sua cuidadora.

Apesar de suas funções mais específicas relacionadas à locomoção, à higiene e à alimentação do estudante, a profissional colaborava também no apoio às atividades escolares, por exemplo, para posicionar o texto para a realização da leitura do aluno ou na realização de uma avaliação em seu computador, posicionando o mouse e o teclado para a melhor realização da prova. 0 ensino ficava por conta da professora Marília $\left(6^{\circ}\right.$ ano do Ensino Fundamental), mas esse auxílio para a acessibilidade à realização das atividades era feito pela cuidadora. Percebe-se a efetividade do trabalho em parceria realizado pela professora e pela cuidadora para a participação do aluno nas atividades escolares. Ao contrário do êxito na parceria relatada nessa experiência, nem sempre há clareza nos papéis dos envolvidos no processo de escolarização do estudante PAEE, fator que dificulta a implementação de um serviço de apoio inclusivo.

Para Stelmachuk e Mazzotta (2012), a atuação dos profissionais de apoio da educação na inclusão escolar poderia ser aprimorada por meio da implementação de políticas públicas, de ações interligadas às secretarias de educação, como a elaboração de normas para a contratação dos auxiliares, determinação das suas atribuições em acordo com as necessidades configuradas pelo contexto escolar em que o aluno com deficiência está inserido e continuidade na oferta de formação continuada e em serviço. No âmbito das unidades escolares, os autores sugerem a atuação dos gestores da educação na "sistematização das orientações aos auxiliares, avaliação periódica dos resultados de sua atuação, garantia de acesso aos professores às avaliações e diagnósticos dos alunos e sistematização da interação entre os profissionais do ensino comum e do atendimento educacional especializado" (STELMACHUK; MAZZOTTA, 2012, p. 200).

Centrar as dificuldades educacionais do estudante PAEE no próprio indivíduo e rotulá-lo como incapaz por causa de sua deficiência pode resultar no desenvolvimento de intervenções individualizadas que pouco ou nada contribuem no aprendizado desse estudante e no impedimento da eliminação das barreiras em todos os demais aspectos: ambientais, atitudinais, físicos, entre outros (BOOTH; AINSCOW, 2012), ao mesmo tempo 
que "obscurece as dificuldades experimentadas pelas crianças sem o rótulo. Isso encoraja as crianças a serem vistas pela lente da 'deficiência' em vez de pessoas integrais” (p. 40).

0 foco em respostas individualizadas em lugar da opção pela remoção de barreiras e implementação de recursos para o desenvolvimento de práticas mais inclusivas pode gerar mais trabalho para o professor e desgaste entre os profissionais, o que em nada contribui para a construção de uma cultura inclusiva na escola. Para Nelson (2014), quando o professor toma uma decisão instrucionalmente focada, deve centralizar sua atenção sobre os resultados para todos. Assim, quando seu objetivo instrucional é orientado pelo DUA, ele direciona o processo de tomada de decisão para como projetar suas atividades, intruções de aprendizagem e os recursos necessários para atingir os resultados esperados para todos os estudantes.

Constatou-se que a atividade da professora Marília (6º ano do Ensino Fundamental) foi potencializada pelo DUA, pois um assunto que comumente seria abordado somente de maneira expositiva envolveu outras estratégias para o aprendizado de todos, como o uso do canal da oralidade e o trabalho em grupo, possibilitando a participação e desenvolvimento de diferentes tarefas por todos, de acordo com suas habilidades e estilos de aprendizagem. Considera-se também que a inserção de um professor de Educação Especial, atuando no modelo de coensino com a professora da sala comum, permitiria fomentar ainda mais as atividades em sala de aula, pois contribuiria com conhecimentos específicos relacionados ao aluno-alvo e às estratégias de acessibilidade ao currículo.

Por outro lado, observou-se que os contextos de trabalho das participantes para continuidade da elaboração e execução de planos de aula fundamentados no DUA apresentaram aspectos práticos desfavoráveis, como a dificuldade de parceria com outros professores da escola, ausência de profissionais da Educação Especial, condições precárias e falta de valorização salarial do trabalho, ausência de tempo e espaços para discussão, planejamento no ambiente escolar, falta de apoio da gestão, entre outros. Entretanto, o programa de formação fomentou elementos propícios, consonantes à maioria das práticas desenvolvidas por elas, como oportunidade de vivência do trabalho colaborativo durante a formação continuada, potencialização das práticas docentes já realizadas, troca e aquisição de conhecimentos, quebra de resistência e de barreiras do ensino e da aprendizagem, atitude de arriscar-se em novas práticas e possibilidade de reflexão sobre a práxis. Destaca-se o encorajamento de inovação em planos de aula que foi incrementado por uma diversidade de estratégias embasadas no conhecimento teórico sobre DUA, encontrando alternativas mais viáveis a todos os estudantes, bem como o compartilhamento das ações de sucesso e insucesso com o grupo de participantes.

A apresentação dos resultados das atividades pautadas no DUA não possuía o caráter avaliativo, de averiguar se as professoras conseguiram ou não desempenhar os planos de aula com sucesso, mas tinha como objetivo contribuir no processo de formação das participantes. Observou-se que o modelo de formação fundamentado pela perspectiva colaborativa possibilitou às professoras o desprendimento de sua habitual rotina e zona de conforto e a exploração de novos meios de ensinar, ampliando suas possibilidades de atingir os objetivos com toda a turma. 


\section{Considerações finais}

As estratégias formativas pautadas nos pressupostos teóricos do DUA e da colaboração mostraram-se ferramentas potencializadoras na formação inicial e continuada dos participantes. Presumem a necessidade de investimento em novos modelos de formação que permitam aos profissionais a vivência desses aspectos durante seu processo formativo, a fim de que tenham um arcabouço que sustente o desenvolvimento de ações docentes mais condizentes com os desafios que a diversidade implica.

$\mathrm{Na}$ falta de uma cultura inclusiva na escola, mesmo que o professor tenha apreendido um novo conhecimento para o aprimoramento de sua prática pedagógica, os resultados mostraram que muitas vezes ele não se sente suficientemente motivado a modificar sua prática, planejar e fazer algo diferente, pois as condições de trabalho e a cultura escolar nem sempre o estimulam nem cobram resultados dos alunos público-alvo da Educação Especial. Nesse contexto, enquanto não se insere uma cultura inclusiva na escola, não se garante a mudança de práticas, fator que os programas de formação continuada, às vezes, conseguem. Apesar de o programa de formação não garantir a sustentabilidade das práticas docentes da maneira vislumbrada inicialmente, é importante apontar os esforços dos participantes em garantir a escolarização dos estudantes PAEE.

Com a apresentação deste estudo, concebeu-se a intenção de contribuir e fomentar reflexões sobre como viabilizar e pensar novos modelos de formação de professores, que dialoguem de maneira mais próxima com os contextos escolares existentes e tão diversos. 0 programa de formação sobre DUA possibilitou a vivência de todo o processo de elaboração, implementação e avaliação de uma formação colaborativa executada por meio dos próprios princípios apresentados aos participantes.

Destacou-se que, por ser uma primeira experiência dos participantes tanto em realizar uma atividade fundamentada no DUA como em construir um planejamento em colaboração, seriam necessários, provavelmente, a elaboração de outras atividades e outros momentos de acompanhamento às professoras para confirmar a permanência dessas ações, o que indicaria a necessidade de estudos posteriores mais prolongados. De qualquer modo, pode-se afirmar que o processo formativo e os resultados advindos das experiências práticas e teóricas possibilitaram o aprendizado de novos conhecimentos e novas alternativas para o ensino que se pretende tornar cada vez mais inclusivo.

\section{Referências}

AINSCOW, Mel; BOOTH, Tony; DYSON, Alan. Improving schools, developing inclusion. London: Routledge, 2006.

ALVES, Maria Manuela; RIBEIRO, Jaime; SIMÕES, Fátima. Universal design for learning (UDL): contributos para uma escola de todos. Indagatio Didactica, Aveiro, v. 5, n. 4, p. 121-146, 2013.

BASTOS, Fabio Bernardo; HENRIQUE, Jose. Pesquisa colaborativa: do isolamento docente a partilha entre pares. In: IBIAPINA, Ivana Maria Lopes de Melo; BANDEIRA, Hilda Maria Martins; ARAUJO, Francisco Antonio Machado (org.). Pesquisa colaborativa: multirreferenciais e práticas convergentes. Teresina: UFPI, 2016. p. 301- 319. 
BEAUCHAMP, Jeanete. Educação especial: relato de experiência. In: PALHARES, Marina Silveira; MARINS, Simone Cristina (org.). Escola inclusiva. São Carlos: UFSCar, 2002. p. 99-104.

BOOTH, Tony; AINSCOW, Mel. Index para a inclusão: desenvolvendo a aprendizagem e a participação nas escolas. Rio de Janeiro: Lapeade, 2012.

BRASIL. Grupo de trabalho da política nacional da educação especial. Política de educação especial na perspectiva da educação inclusiva. Brasília, DF: MEC/SEESP, 2008.

BUENO, José Geraldo Silveira. As políticas de inclusão escolar: uma prerrogativa de educação especial? In: BUENO, José Geraldo Silveira; MENDES, Geovana Mendonça Lunardi; SANTOS, Roseli Albino (org.). Deficiência e escolarização: novas perspectivas de análise. Araraquara: Junqueira \& Marin, 2008. p. 43-63.

CAPELLINI, Vera Lúcia Messias Fialho. Avaliação das possibilidades do ensino colaborativo no processo de inclusão escolar do aluno com deficiência mental. 2004. Tese (Doutorado em Educação Especial) Centro de Educação e Ciências Humanas, Universidade Federal de São Carlos, São Carlos, 2004.

CAST UDL BOOK BUILDER. Book Builder, 2013. Homepage. Disponível em: http://bookbuilder.cast.org/. Acesso em: 16 mar. 2019.

INEP. Instituto Nacional de Estudos e Pesquisas Educacionais Anísio Teixeira. Sinopses estatísticas da educação básica. Brasília, DF: INEP, 2002. Disponível em: http://portal.inep.gov.br/web/guest/sinopsesestatisticas-da-educacao-basica. Acesso em: 20 maio 2020.

INEP. Instituto Nacional de Estudos e Pesquisas Educacionais Anísio Teixeira. Sinopses estatísticas da educação básica. Brasília, DF: INEP, 2019. Disponível em: http://portal.inep.gov.br/web/guest/sinopsesestatisticas-da-educacao-basica. Acesso em: 20 maio 2020.

JOHNSON-HARRIS, Kimberly; MUNDSCHENK, Nancy. Working effectively with students with BD in a general education classroom: the case for universal design for learning. The Clearing House, London, v. 87, n. 4, p. 168-174, 2014.

KING-SEARS, Peggy. Introduction to learning disability quarterly special series on universal design for learning: part one of two. Learning Disability Quarterly, Thousand Oaks, v. 37, n. 2, p. 68-70, 2014.

KOVALESKI, Joseph; BLACK, Lynanne. Multi-tier service delivery: current status and future directions. In: GLOVER, Todd; VAUGHN, Sharon (ed.). The promise of response to intervention: evaluating current science and practice. New York: Guilford, 2010. p. 23-56.

LOPES, Alice Ribeiro Casimiro. Pluralismo cultural: preconizando o consenso ou assumindo o conflito? Espaço, Rio de Janeiro, n. 8, p. 31-37, 1997.

MIZUKAMI, Maria da Graça Nicoletti et al. Escola e aprendizagem da docência: processos de investigação e formação. São Carlos: UFSCar, 2003.

NELSON, Loui Lord. Design and deliver: planning and teaching using universal design for learning. Baltimore: Brookes Publishing Company, 2014. 
NUNES, Clarisse; MADUREIRA, Isabel Pizarro. Desenho universal para a aprendizagem: construindo práticas pedagógicas inclusivas. Da Investigação às Práticas, Lisboa, v. 5, n. 2, p. 126-143, 2015.

RABELO, Lucélia Cardoso Cavalcante. Ensino colaborativo como estratégia de formação continuada de professores para favorecer a inclusão escolar. 2012. Tese (Mestrado em Educação Especial) Centro de Educação e Ciências Humanas, Universidade Federal de São Carlos, São Carlos, 2012.

STAINBACK; Susan; STAINBACK, William. Inclusão: um guia para educadores. Porto Alegre: Artmed, 1999.

STELMACHUK, Anaí Cristina da Luz; MAZZOTTA, Marcos José da Silveira. Atuação de profissionais da educação na inclusão escolar do aluno com deficiência intelectual. Educação Especial, Santa Maria, v. 25, n. 43, p. 185-202, 2012.

TOLEDO, Elizabete Humai; VITALIANO, Célia Regina. Formação de professores por meio de pesquisa colaborativa com vistas à inclusão de alunos com deficiência intelectual. Revista Brasileira de Educação Especial, Marília, v. 18, n. 2, p. 319-336, 2012.

VILARONGA, Carla Ariela Rios. Colaboração da educação especial em sala de aula: formação nas práticas pedagógicas do coensino. 2014. Tese (Doutorado em Educação Especial) - Centro de Educação e Ciências Humanas, Universidade Federal de São Carlos, São Carlos, 2014.

VITALIANO, Célia Regina; MANZINI, Eduardo José. A formação inicial de professores para inclusão de alunos com necessidades educacionais especiais. In: VITALIANO, Célia Regina. Formação de professores para a inclusão de alunos com necessidades educacionais especiais. Londrina: UEL, 2010. p. 49-112.

WANG, Margaret; REYNOLDS, Maynard; WALBERG, Herbert. Handbook of special and remedial education: research and practice. Oxford: Pergamon, 1995.

WANG, Mian; FITCH, Paul. Preparing pre-service teachers for effective co-teaching in inclusive classrooms. In: FORLIN, Chris (org.). Teacher education for inclusion: changing paradigms and innovative approaches. London: Routledge, 2010. p. 113-119.

ZERBATO, Ana Paula. Desenho universal para a aprendizagem na perspectiva da inclusão escolar: potencialidades e limites de uma formação colaborativa. 2018. Tese (Doutorado em Educação Especial) Centro de Educação e Ciências Humanas, Universidade Federal de São Carlos, São Carlos, 2018.

Recebido em: 05.02.2020

Revisado em: 14.05.2020

Aprovado em: 30.06 .2020

Ana Paula Zerbato é docente da Faculdade de Educação da Universidade de São Paulo (FEUSP), do Departamento de Metodologia do Ensino e Educação Comparada, na área da Educação Especial. Mestre e doutora em Educação Especial pela Universidade Federal de São Carlos. 
Enicéia Gonçalves Mendes é docente titular da Universidade Federal de São Carlos, do Departamento de Psicologia, do Programa de Pós-graduação em Educação Especial. Coordenadora do Observatório Nacional de Educação Especial (ONEESP), líder do Grupo de Pesquisa sobre Formação de Recursos Humanos em Educação Especial (GP-FOREESP). 